\title{
One Health Surveillance with Electronic Integrated Disease Surveillance System
}

\author{
Alexey V. Burdakov*, Andrey O. Ukharov and Thomas G. Wahl \\ Black \& Veatch, Overland Park, KS, USA
}

\section{Objective}

The objective of this demonstration is to show conference attendees how one-health surveillance in medical, veterinary and environmental sectors can be improved with Electronic Integrated Disease Surveillance System (EIDSS) using CCHF as an example from Kazakhstan.

\section{Introduction}

EIDSS supports collection and analysis of epidemiological, clinical and laboratory information on infectious diseases in medical, veterinary and environmental sectors. At this moment the system is deployed in Kazakhstan at 150 sites (planned 271) in the veterinary surveillance and at 8 sites (planned 23) in human surveillance. The system enforces the one-health concept and provides capacity to improve surveillance and response to infectious disease including especially dangerous like CCHF.

EIDSS has been in development since 2005 and is a free-of-charge tool with plans for open-source development. The system development is based on expertise of a number of US and international experts including CDC, WRAIR, USAMRIID, et al.

\section{Methods}

Effective monitoring and control of zoonotic diseases requires integrated approach to surveillance in medical, veterinary and environmental sectors. Capability to rapidly collect and analyze information from these sectors is challenging due to diversity of different systems often used in these areas. EIDSS presented a unique integrated solution which allows collecting, sharing and analyzing data across these sectors. In those countries where this system is implemented both in human and veterinary surveillance (Georgia, Azerbaijan and Kazakhstan), it provides a unique opportunity to improve monitoring and control capability.

In Kazakhstan and other countries experts are working on creating and improving effective analysis methods. In particular a method of real-time control of CCHF situation was developed in Kazakhstan. It allows the assembly of raw data gathered at the lower level in, surveillance system throughout the country on CCHF cases in humans, assemble ticks vector surveillance campaigns and laboratory diagnostic results and analyze these data against population density. This gives a one-step tool to an epidemiologist to understand the situation and plan response at the national and regional level (see sample map). A quick link with the veterinary response teams allow to rapidly act with domestic animals prophylaxis measures.

Demonstration of the tool encouraging the One Health approach to the surveillance which is already in place in a number of countries provides an exclusive opportunity to review different aspects of its utilization in practice as well as discuss challenges and benefits of this method in resource limited environments.

\section{Conclusions}

EIDSS provides a capacity to improve one-health disease surveillance in human, veterinary and vector sectors by rapidly collecting, disseminating and analyzing data on infectious diseases. Particular methods which are being developed in Kazakhstan and other participating countries provide an instrument to epidemiologists to make decisions and more effectively plan response measures. Currently particular methods were tested for CCHF infection. It is planned to introduce methods for brucellosis and other infectious diseases of special interest in Central Asia and Caucasus Region.

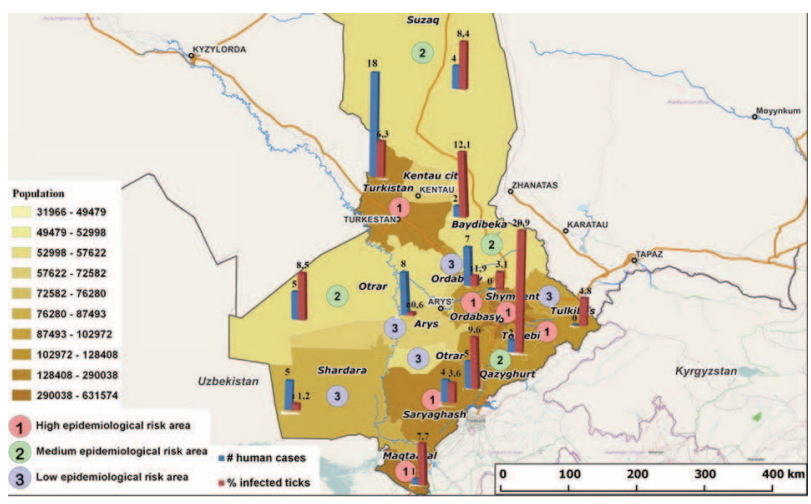

\section{Keywords}

EIDSS; electronic surveillance; one-health

\section{References}

1. Burdakov A., Ukharov A. Transforming national human and veterinary disease surveillance systems from paper into integrated electronic form in the FSU countries // 15th International Congress on Infectious Diseases (ICID), Bangkok 2012

2. Burdakov A., Ukharov A. Electronic Integrated Disease Surveillance (EIDSS) // World Congress on Information and Communication Technologies for Development (WCID’09) congress in Beijing, China 2009

3. Burdakov A. Implementation of Information-Telecommunication part of the Threat Agent Detection and Response (TADR) program in Republic of Kazakhstan // Official Bulletin of State Sanitary-Epidemiological Service of Republic of Kazakhstan, 1/37. 69-70.

\section{*Alexey V. Burdakov}

E-mail: BurdakovAV@bv.com 